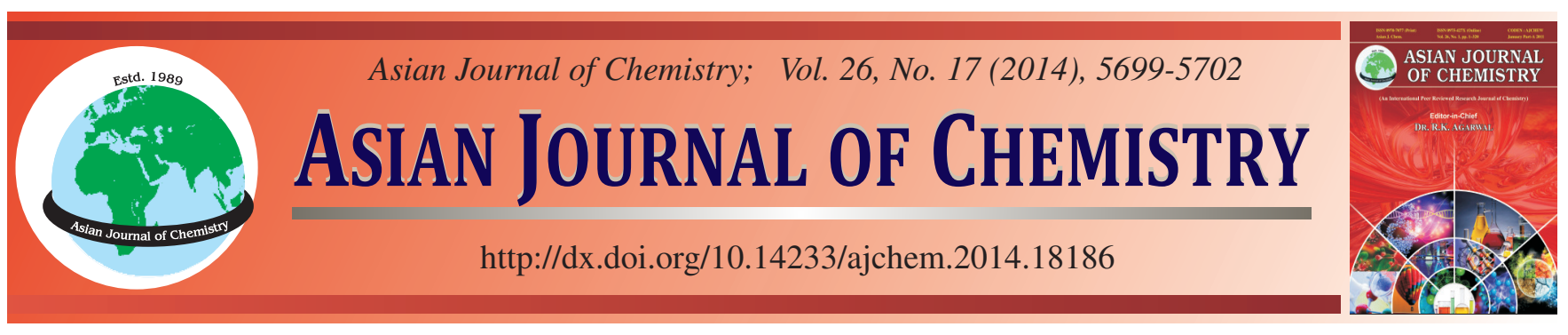

\title{
Theoretical Study on Cracking Moment of Normal Section of Concrete Beams Reinforced with FRP Bars $\dagger$
}

\author{
B. JiA ${ }^{*}$, S.T. ZHU, S.F. LiU and X. LiU
}

School of Civil Engineering and Architecture, Southwest University of Science and Technology, Mianyang, P.R. China

*Corresponding author: Tel: +86 13689683022; E-mail: jiabin216@126.com

The cracking moment is an important indicator to measure the crack resistance and durability of concrete beams reinforced with FRP bars. In order to establish the computational formula of cracking moment of FRP reinforced concrete beam, a sectional plasticity influence coefficient of resistance moment which could be applied to reflect the plastic deformation of concrete in tensile region, was introduced. Moreover, the value of the coefficient was obtained based on the tested experimental data collected from the literature. The theoretical results were compared to the test results of beam cracking moments, as well to the values calculated by American code ACI 440.1 R-06, it turned out that the calculation formula established in this paper had a good applicability and could provide some design guideline for the flexural members reinforced with FRP bars.

Keywords: FRP Bars, Concrete beams, Cracking moment.

ᄂ - - - - - - - - - - - - - - - - - - - - - - - - -

\section{INTRODUCTION}

Steel corrosion in concrete structure results from concrete carbonation and aggressive environments, leading to the degradation of crack resistance and durability of steel reinforced concrete component. As one of the most innovative composite materials, FRP bars have characteristics of high specific strength, excellent corrosion resistance and strong design ability ${ }^{1-3}$, which have emerged as a potential alternative material to the traditional steel. The cracking moment of a normal section is not just the main basis to determine whether a component cracks, but also an important indicator to evaluate structural service performance and durability, thus it is a great significance to study the cracking moment of FRP reinforced concrete beams.

Several scholars involved in the study on cracking moment of a normal section of FRP reinforced concrete beams early. Masmoudi et al. ${ }^{4}$ investigated the cracking behaviour of FRP reinforced concrete beams and concluded that the number of crack increased while the crack spacing decreased as the reinforcement ratio increased. They also pointed out that the cracking moment should be computed as recommended by ACI, that was, by assuming that the section of the beam was made only of concrete. Rafi et al. ${ }^{5}$ compared the cracking loads and cracking patterns of concrete beams reinforced with CFRP bars and steel bars, respectively. They found that the cracking behaviour and pattern of both steel and CFRP reinforced beams were similar. Nowadays, the formulas of cracking moment of FRP reinforced concrete beams have been put into the American code ACI 440. 1 R-06 6 , but it is based on the elastic section moment of inertia and not considering the plastic deformation of concrete in tensile area. Zhang and $\mathrm{Huo}^{7}, \mathrm{Li}$ and Jiang ${ }^{8}$ used three point loading test to investigate the cracking behaviour of BFRP reinforced concrete beams and stated that reinforcement ratio had very small effect on the cracking moment. Although many experiments have been carried on, there is still lack of a specific formula to calculate the cracking moment. In this paper, the calculation formula, which considering the plastic strain of concrete in tensile area will be established.

\section{Theoretical analysis on cracking moment of FRP reinforced concrete beams}

Uncracked transformed moment of inertia: FRP bar has a significantly lower compressive strength than tensile strength and is subject to significant variation. Therefore, the strength of any FRP bar in compression should be ignored and using single-side reinforced rectangular section in design calculations. Based on the principle of equal strength to transform the FRP bars into concrete and carring on theoretical derivation. 
The reinforced area of FRP bars in tensile region, $A_{f}$, is transformed into concrete and gets the transformed area $\mathrm{kA}_{\mathrm{f}}$, in which $\mathrm{k}=\varepsilon_{\mathrm{f}} / \varepsilon_{\mathrm{c}}, \varepsilon_{\mathrm{f}}$ and $\varepsilon_{\mathrm{c}}$ are the elastic modulus of FRP bars and steel bars, respectively. Therefore, the extra area, $(\mathrm{K}-1) \mathrm{A}_{\mathrm{f}}$, is added at the same height, as shown in Fig. 1. So the total area of concrete after transformed can be expressed as eqn. 1 .
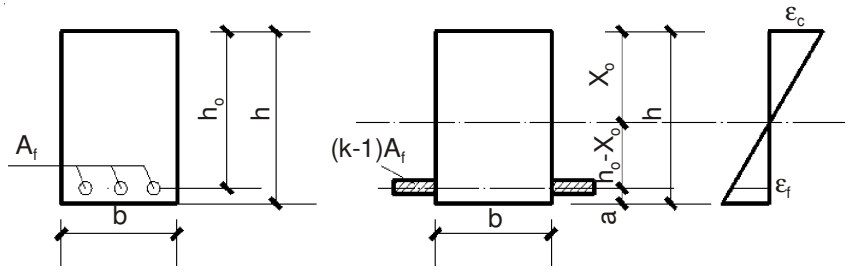

Fig. 1. Transformed section before cracking

$$
\mathrm{A}_{0}=\mathrm{bh}+(\mathrm{k}-1) \mathrm{A}_{\mathrm{f}}
$$

where $A_{0}$ and $A_{f}$ are transformed area of concrete and reinforced area of FRP bars, respectively, $b$ and $h$ are the cross section width and depth of the concrete beam.

The distance from extreme compression concrete to the neutral axis can be determined by the condition of equal moment of area for tensile and compressive regions, respectively, as shown in eqns. 2 and 3 , where $h_{0}$ is the effective depth.

$$
\begin{aligned}
& \frac{1}{2} \mathrm{bx}_{0}^{2}+\frac{1}{2} \mathrm{~b}\left(\mathrm{~h}-\mathrm{x}_{0}\right)^{2}+(\mathrm{k}-1) \mathrm{A}_{\mathrm{f}}\left(\mathrm{h}_{0}-\mathrm{x}_{0}\right) \\
& \mathrm{x}_{0}=\left(\frac{1}{2} \mathrm{bh}^{2}+(\mathrm{k}-1) \mathrm{A}_{\mathrm{f}} \mathrm{h}_{0}\right)\left(\mathrm{bh}+(\mathrm{k}-1) \mathrm{A}_{\mathrm{f}}\right)^{-1}
\end{aligned}
$$

The transformed moment of inertia of an area can be calculated with eqn. 4 .

$$
\mathrm{I}_{0}=\frac{\mathrm{b}}{3}\left[\mathrm{x}_{0}^{3}+\left(\mathrm{h}-\mathrm{x}_{0}\right)^{3}\right]+(\mathrm{k}-1) \mathrm{A}_{\mathrm{f}}\left(\mathrm{h}_{0}-\mathrm{x}_{0}\right)^{2}
$$

Expression of the cracking moment: Based on the plane assumption, no extrusion between the vertical lines and deformation within the elastic limit, the expression of normal stress as shown in eqn. 5 in mechanics of materials.

$$
\sigma=\mathrm{MW}^{-1}=(\mathrm{My}) \mathrm{I}_{\mathrm{z}}^{-1}
$$

when the beam cracks, $\sigma=f_{t}$, where $f_{t}$ is tensile strength of concrete, so the cracking moment can be calculated with eqn. 6 .

$$
M_{c r}=\left(f_{t} I_{0}\right)\left(h-x_{0}\right)^{-1}
$$

In fact, part of the concrete in tensile area has entered the stage of plastic deformation when the beams are about to crack and no longer satisfying the assumption of deformation within the elastic limit. In this view, the eqn. 6 is modified by the introduction of sectional plasticity influence coefficient of resistance moment $\gamma$ and the final calculation formula which considering the plastic strain of concrete in tensile region will be obtained, as shown in eqn. 7 .

$$
\mathrm{M}_{\mathrm{cr}}=\left(\gamma \mathrm{f}_{\mathrm{t}} \mathrm{I}_{0}\right)\left(\mathrm{h}-\mathrm{x}_{0}\right)^{-1}
$$

Analysis of sectional plasticity influence coefficient of resistance moment $\gamma$ : Based on the tested experimental data of the cracking moment which contains 14 GFRP, 20 CFRP, 6 BFRP and 4 AFRP reinforced concrete beams, respectively. The values of sectional plasticity influence coefficient under every working condition will be got by plug the data into eqn. 7 and fitting out the average value with statistical methods, as shown in Tables 1-4.

Tables 1-4 show that the value of $\gamma$ range from 1.05 to 1.27 and concentrate at 1.1 to 1.17 when the reinforced ratio from 0.2 to $1.5 \%$ and concrete strength grade from C30 to C60, as shown in Fig.2. What's more, the values of $\gamma$ are very close for different kinds of FRP reinforced concrete beams. In this paper, $\gamma=1.14$ is proposed for considering the structural safety stock and Convenient application.

Verification of the cracking moment of FRP reinforced concrete beams: ACI 440.1R-06 offers the following expression $^{6}$ to calculate the cracking moment:

$$
M_{c r}=\left(2 f_{t} I_{g}\right) h^{-1}
$$

where $f_{t}$ is the tensile strength of concrete, $I_{g}=b h^{3} / 12$ is the

\begin{tabular}{|c|c|c|c|c|c|c|c|c|c|c|c|}
\hline \multicolumn{12}{|c|}{$\begin{array}{c}\text { TABLE-1 } \\
\text { VALUE OF } \gamma \text { OF CONCRETE BEAM REINFORCED WITH GFRP BARS }\end{array}$} \\
\hline Reference & $\mathrm{b}(\mathrm{mm})$ & $\mathrm{h}(\mathrm{mm})$ & $\rho_{\mathrm{f}}(\%)$ & $\mathrm{f}_{\mathrm{t}}(\mathrm{MPa})$ & K & $\mathrm{x}_{0}(\mathrm{~mm})$ & $\mathrm{M}_{\mathrm{cr}, \mathrm{ex}}(\mathrm{kNm})$ & $\gamma$ & $\mathrm{AVG}^{\mathrm{a}}$ & STDEV $^{b}$ & $\mathrm{CV}^{\mathrm{c}}$ \\
\hline \multirow{3}{*}{$\begin{array}{l}\text { Alsuna and } \\
\text { Pilakoutas }\end{array}$} & 150 & 250 & 0.7 & 3.4 & 1.4 & 125 & 4.5 & $0.84^{\mathrm{d}}$ & \multirow{14}{*}{1.17} & \multirow{14}{*}{0.065} & \multirow{14}{*}{0.055} \\
\hline & 150 & 250 & 0.80 & 3.4 & 1.4 & 125 & 5.7 & 1.06 & & & \\
\hline & 150 & 250 & 3.80 & 3.4 & 1.4 & 127 & 6.2 & 1.12 & & & \\
\hline \multirow{4}{*}{$\begin{array}{l}\text { Kassem } \\
\text { et al. }{ }^{10}\end{array}$} & 200 & 300 & 1.60 & 2.9 & 1.4 & 151 & 10.9 & 1.24 & & & \\
\hline & 200 & 300 & 2.20 & 2.9 & 1.4 & 151 & 11.3 & 1.27 & & & \\
\hline & 200 & 300 & 1.40 & 2.9 & 1.3 & 150 & 10.1 & 1.15 & & & \\
\hline & 200 & 300 & 1.90 & 2.9 & 1.3 & 150 & 11.3 & 1.26 & & & \\
\hline \multirow{4}{*}{$\begin{array}{l}\text { Wong } \\
\text { and } \mathrm{Qi}^{11}\end{array}$} & 180 & 200 & 0.54 & 3.75 & 1.2 & 100 & 4.5 & 1.14 & & & \\
\hline & 180 & 200 & 0.54 & 3.75 & 1.2 & 100 & 4.8 & 1.21 & & & \\
\hline & 180 & 200 & 0.81 & 3.75 & 1.2 & 100 & 4.5 & 1.14 & & & \\
\hline & 180 & 200 & 0.81 & 3.75 & 1.2 & 100 & 5.3 & $1.35^{\mathrm{d}}$ & & & \\
\hline \multirow{3}{*}{ Zhang et al. ${ }^{12}$} & 200 & 300 & 0.92 & 3.04 & 1.1 & 160 & 13.4 & 1.22 & & & \\
\hline & 200 & 300 & 0.83 & 3.04 & 1.1 & 160 & 13.1 & 1.15 & & & \\
\hline & 200 & 300 & 0.81 & 3.04 & 1.1 & 160 & 12.6 & 1.11 & & & \\
\hline
\end{tabular}
gross moment of inertia.

Calculating the cracking moment by eqns. 7 and 8 to verify the proposed theoretical equation based on the experimental data of Toutanji and Saafi ${ }^{17}$ and Zorislav ${ }^{18}$, as shown in Table-5.

Table- 5 shows that the average and square deviation of the ratio between predicted and experimental cracking moment are 0.87 and 0.023 , respectively, which means that the predicted

${ }^{a}$ Average. ${ }^{\mathrm{b}}$ Standard deviation. ${ }^{\mathrm{c} C o e f f i c i e n t}$ of variability. ${ }^{\mathrm{d}}$ Don't participate in calculation. 


\begin{tabular}{|c|c|c|c|c|c|c|c|c|c|c|c|}
\hline \multicolumn{12}{|c|}{$\begin{array}{c}\text { TABLE-2 } \\
\text { LUE OF } \gamma \text { OF CONCRETE BEAM REINFORCED WITH CFRP BARS }\end{array}$} \\
\hline Reference & $\mathrm{b}(\mathrm{mm})$ & $\mathrm{h}(\mathrm{mm})$ & $\rho_{\mathrm{f}}(\%)$ & $\mathrm{f}_{\mathrm{t}}(\mathrm{MPa})$ & K & $\mathrm{x}_{0}(\mathrm{~mm})$ & $\mathrm{M}_{\mathrm{cr}, \mathrm{ex}}(\mathrm{kN} \mathrm{m})$ & $\gamma$ & AVG & STDEV & $\mathrm{CV}$ \\
\hline \multirow{5}{*}{$\begin{array}{l}\mathrm{Ou} \\
\text { et al. }\end{array}$} & 100 & 200 & 0.22 & 2.54 & 4.3 & 100 & 1.7 & 1.17 & \multirow{19}{*}{1.12} & \multirow{19}{*}{0.041} & \multirow{19}{*}{0.035} \\
\hline & 100 & 200 & 0.22 & 2.54 & 4.3 & 100 & 1.6 & 1.16 & & & \\
\hline & 100 & 200 & 0.22 & 2.54 & 4.3 & 100 & 1.3 & $0.87^{\mathrm{a}}$ & & & \\
\hline & 100 & 200 & 0.22 & 2.64 & 4.2 & 100 & 1.8 & $1.27^{\mathrm{a}}$ & & & \\
\hline & 100 & 200 & 0.22 & 2.64 & 4.2 & 100 & 1.7 & 1.12 & & & \\
\hline \multirow{2}{*}{$\mathrm{Xu}^{14}$} & 180 & 250 & 0.37 & 3.11 & 4.5 & 126 & 5.2 & 1.08 & & & \\
\hline & 180 & 250 & 0.48 & 3.11 & 4.5 & 127 & 5.46 & 1.10 & & & \\
\hline \multirow{6}{*}{$\begin{array}{l}\text { Kassem } \\
\text { et al. }{ }^{10}\end{array}$} & 200 & 300 & 0.60 & 3.94 & 4.0 & 152 & 11.57 & 1.13 & & & \\
\hline & 200 & 300 & 0.60 & 3.94 & 4.0 & 152 & 11.68 & 1.14 & & & \\
\hline & 200 & 300 & 0.90 & 3.89 & 4.0 & 153 & 11.77 & 1.16 & & & \\
\hline & 200 & 300 & 1.20 & 3.89 & 4.0 & 152 & 11.27 & 1.19 & & & \\
\hline & 200 & 300 & 0.50 & 3.92 & 4.0 & 153 & 11.86 & 1.16 & & & \\
\hline & 200 & 300 & 0.50 & 3.92 & 4.0 & 154 & 11.76 & 1.15 & & & \\
\hline \multirow{6}{*}{$\begin{array}{l}\text { Rafi } \\
\text { et al. }\end{array}$} & 200 & 300 & 0.80 & 3.96 & 4.1 & 153 & 11.02 & 1.05 & & & \\
\hline & 200 & 300 & 1.10 & 3.96 & 4.1 & 154 & 11.91 & 1.10 & & & \\
\hline & 120 & 200 & 2.77 & 3.88 & 4.1 & 105 & 2.63 & 1.06 & & & \\
\hline & 120 & 200 & 2.77 & 3.78 & 4.1 & 105 & 2.53 & 1.07 & & & \\
\hline & 120 & 200 & 0.32 & 3.66 & 4.1 & 106 & 2.4 & 1.11 & & & \\
\hline & 120 & 200 & 0.32 & 3.61 & 4.1 & 106 & 2.4 & 1.10 & & & \\
\hline
\end{tabular}

TABLE-3

VALUE OF $\gamma$ OF CONCRETE BEAM REINFORCED WITH BFRP BARS

\begin{tabular}{|c|c|c|c|c|c|c|c|c|c|c|c|}
\hline Reference & $\mathrm{b}(\mathrm{mm})$ & $\mathrm{h}(\mathrm{mm})$ & $\rho_{\mathrm{f}}(\%)$ & $\mathrm{f}_{\mathrm{t}}(\mathrm{MPa})$ & $\mathrm{K}$ & $\mathrm{x}_{0}(\mathrm{~mm})$ & $\mathrm{M}_{\mathrm{cr}, \mathrm{ex}}(\mathrm{kNm})$ & $\gamma$ & $\mathrm{AVG}^{\mathrm{a}}$ & STDEV $^{\mathrm{b}}$ & $\mathrm{CV}^{\mathrm{c}}$ \\
\hline \multirow{3}{*}{$\begin{array}{l}\text { Huo } \\
\text { et al. }\end{array}$} & 200 & 300 & 0.36 & 3.1 & 1.4 & 150 & 10.5 & 1.13 & \multirow{6}{*}{1.13} & \multirow{6}{*}{0.013} & \multirow{6}{*}{0.012} \\
\hline & 200 & 300 & 0.77 & 3.1 & 1.4 & 150 & 10.6 & 1.13 & & & \\
\hline & 200 & 300 & 1.15 & 3.3 & 1.4 & 151 & 12 & $1.19^{\mathrm{a}}$ & & & \\
\hline \multirow{3}{*}{ Li et $a l .{ }^{16}$} & 200 & 300 & 0.21 & 3.13 & 1.3 & 150 & 7.12 & $1.04^{\mathrm{a}}$ & & & \\
\hline & 200 & 300 & 0.29 & 3.13 & 1.3 & 150 & 7.37 & 1.11 & & & \\
\hline & 200 & 300 & 0.44 & 3.13 & 1.3 & 150 & 7.45 & 1.14 & & & \\
\hline
\end{tabular}

${ }^{a}$ Don't participate in calculation.

TABLE-4

VALUE OF $\gamma$ OF CONCRETE BEAM REINFORCED WITH AFRP BARS

\begin{tabular}{cccccccccccc}
\hline Reference & $\mathrm{b}(\mathrm{mm})$ & $\mathrm{h}(\mathrm{mm})$ & $\rho_{\mathrm{f}}(\%)$ & $\mathrm{f}_{\mathrm{t}}(\mathrm{MPa})$ & $\mathrm{K}$ & $\mathrm{x}_{0}(\mathrm{~mm})$ & $\mathrm{M}_{\text {cr,ex }}(\mathrm{kNm})$ & $\gamma$ & $\mathrm{AVG}^{\mathrm{a}}$ & $\mathrm{STDEV}^{\mathrm{b}}$ & $\mathrm{CV}^{\mathrm{c}}$ \\
\hline \multirow{3}{*}{ Kassem } & 200 & 300 & 0.9 & 2.9 & 1.7 & 151 & 10.1 & 1.13 & & & \\
et al. $^{10}$ & 200 & 300 & 0.9 & 2.9 & 1.7 & 151 & 10 & 1.13 & 1.16 & 0.035 & 0.030 \\
& 200 & 300 & 1.2 & 2.9 & 1.7 & 151 & 10.5 & 1.17 & & \\
\hline
\end{tabular}

TABLE-5

COMPARISON OF CRACKING MOMENT

\begin{tabular}{|c|c|c|c|c|c|c|c|}
\hline Reference & FRP bar & $\mathrm{M}_{\mathrm{cr}, \mathrm{ex}}(\mathrm{Kn} \mathrm{m})$ & $\mathrm{M}_{\mathrm{cr}, \gamma=1.14}$ & $\mathrm{M}_{\mathrm{cr}, \mathrm{ACI}}(\mathrm{kN} \mathrm{m})$ & $\mathrm{M}_{\mathrm{cr}, \gamma=1.14} / \mathrm{M}_{\mathrm{cr}, \mathrm{ex}}$ & $\mathrm{M}_{\mathrm{cr}, \mathrm{ACl}} / \mathrm{M}_{\mathrm{cr}, \mathrm{ex}}$ & $\mathrm{M}_{\mathrm{cr}, \gamma=1.14} / \mathrm{M}_{\mathrm{cr}, \mathrm{ACI}}$ \\
\hline \multirow{4}{*}{$\begin{array}{l}\text { Toutanji and } \\
\text { Saafi }^{17}\end{array}$} & GFRP & 11.7 & 10.3 & 10.09 & 0.88 & 0.86 & 1.02 \\
\hline & GFRP & 12.3 & 10.3 & 10.09 & 0.84 & 0.82 & 1.02 \\
\hline & GFRP & 13.4 & 11.1 & 10.09 & 0.83 & 0.75 & 1.1 \\
\hline & GFRP & 12.8 & 11.1 & 10.09 & 0.86 & 0.78 & 1.1 \\
\hline \multirow{3}{*}{ Zorislav $^{18}$} & CFRP & 6.1 & 5.3 & 4.8 & 0.88 & 0.78 & 1.1 \\
\hline & CFRP & 5.9 & 5.3 & 4.8 & 0.89 & 0.81 & 1.1 \\
\hline & CFRP & 6 & 5.3 & 4.8 & 0.88 & 0.80 & 1.1 \\
\hline
\end{tabular}

values are smaller than the experimental values about $10 \%$ and it is advantageous to judge the component cracking with the eqn. 7. As can be seen from the results, the predictions obtained from the current study are larger than the values calculated by ACI 440.1R-06 about 2-10\%, for considering the effect of the plastic deformation of concrete in tensile area, so the calculation model is more close to the actual deformation and the results will be more accurate.

\section{Conclusion}

A method to calculate the cracking moment of FRP concrete beams based on the tested experimental data had been established. It was found that the computational formula of cracking moment had a good applicability after the comparison with the American code and reliability analysis. The sectional plasticity influence coefficient of resistance moment that is suitable for FRP concrete beams was obtained and it was 


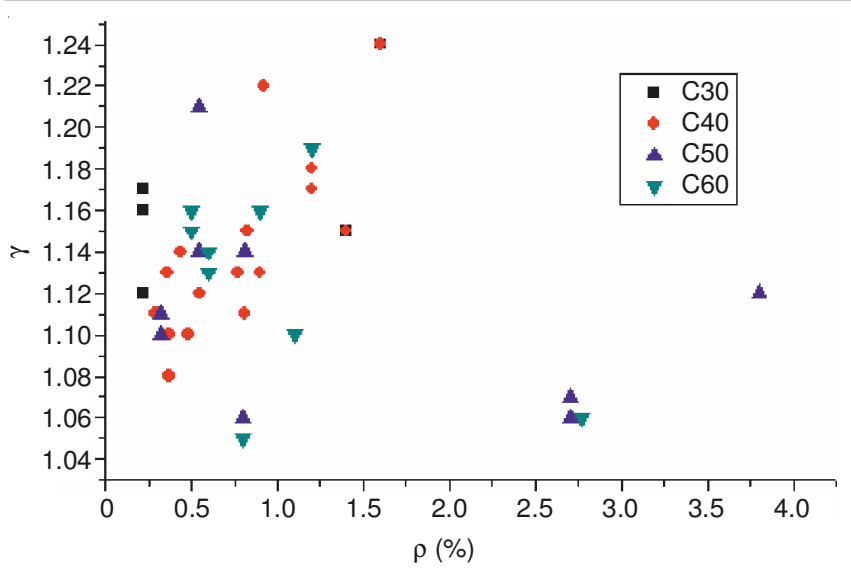

Fig. 2. Distribution of $\gamma$

slightly affected by reinforced ratio and concrete strength grade, In this paper, $\gamma=1.14$ was proposed for accounting for the structural safety stock and easy application.

\section{ACKNOWLEDGEMENTS}

This work was financially supported by Ph.D. Programs Foundation of the Southwest University of Science and Technology (11zx7158).

\section{REFERENCES}

1. W.C. Xue, J. Hohai Univ., 35, 19 (1997).

2. H. Zhu and Y. Qian, J. Architect. Civil Eng., 23, 31 (2006).

3. B.R. Huo and X.D. Zhang, J. Shenyang Jianzhu Univ., 7, 629 (2011).

4. R. Masmoudi, B. Benmokrane and O. Chaallal, J. Civ. Eng., 23, 1174 (1996).

5. M. Rafi, A. Nadjai, F. Ali and D. Talamona, Constr. Building Mater., 22, 277 (2008).

6. ACI Committee 440, 1R, American Concrete Institute (2006).

7. X.D. Zhang and B.R. Huo, J. Shenyang Jianzhu Univ., 8, 348 (2012).

8. B.H. Li and S.Y. Jiang, China Plastics, 7, 48 (2009).

9. R. Al-Sunna, K. Pilakoutas, I. Hajirasouliha and M. Guadagnini, Composites Part B, 43, 513 (2012).

10. C. Kassem, A. Farghaly and B. Benmokrane, J. Compos. Constr., 15, 682 (2011).

11. C.G. Wong and K. Qi, Fujian Architecture Constr., 6, 38 (2007).

12. Z.Q. Zhang, X.Q. Shi and Z.Y. Li, J. Southwest JiaoTong Univ., 46, 746 (2011).

13. J.P. Ou, B. Wang and Z. He, China Civil Eng. J., 38, 11 (2005).

14. X.S. Xu, Tianjin University (2007).

15. B.R. Huo, X.D. Zhang and Y. Song, Ind. Constr., 41, 45 (2011).

16. B.H. Li, S.Y. Jiang, W. Fei and H.L. Zhou, China Plastics, 23, 71 (2009).

17. H. Toutanji and M. Saafi, ACI Struct. J., 97, 712 (2000).

18. Z. Soric, T. Kisicek and J. Galic, Mater. Struct., 43, 73 (2010). 